\title{
NÃO PREFERÊNCIA PARA OVIPOSIÇÃO E ALIMENTAÇÃO POR TUTA ABSOLUTA (MEYRICK) EM GENÓTIPOS DE TOMATEIRO
}

\author{
A.L. Boiça Junior, D.B. Bottega, A.L. Lourenção, N.E.L. Rodrigues
}

Universidade Estadual Paulista, Faculdade de Ciências Agrárias e Veterinárias, Departamento de Fitossanidade, Laboratório de Resistência de Plantas a Insetos, Via de Acesso Prof. Paulo Donato Castellane, s/no , CEP 14884-900, Jaboticabal, SP, Brasil. E-mail: aboicajr@fcav.unesp.br

\section{RESUMO}

Este trabalho buscou selecionar genótipos de tomateiro resistentes a Tuta absoluta (Meyrick) (Lepidoptera: Gelechiidae), dos tipos não preferência para oviposição e alimentação, em testes com e sem chance de escolha. As espécies utilizadas foram Solanum lycopersicum L. (cv. Santa Clara, os híbridos: Saladete Italiano Ty Tyna, Santa Cruz Débora Ty, Salada Lumi, Saladete Italiano Andrea Victory e Santa Cruz Ty Carina Ty), S. habrochaites S. Knapp \& D.M Spooner (linhagens PI 134417 e PI 134418) e S. pimpinellifolium L. (linhagens NAV 1062 e PI 126931). Nos testes de não preferência para oviposição, foram contados o número de ovos por planta às 24, 48 e 72 horas, após a liberação dos adultos. Para os testes de não preferência para alimentação, foram avaliados a atratividade das larvas pelos genótipos em cada repetição a 1, 3, 5, 10, 30, 60, 120, 360, 720 e 1440 minutos, após a liberação das larvas e massa consumida pelas larvas. Constatou-se que os genótipos de tomateiro avaliados não apresentam resistência dos tipos não preferência para oviposição. Já o genótipo PI 134417 apresenta resistência do tipo não preferência para alimentação.

PALAVRAS-CHAVE: Resistência de plantas, tipos de resistência, aleloquímicos.

\section{ABSTRACT}

RESISTANCE IN TOMATO GENOTYPES TO ATTACK OF TUTA ABSOLUTA (MEYRICK, 1917) (LEPIDOPTERA: GELECHIIDAE):NON-PREFERENCEFOROVIPOSITION ANDFEEDING. This study aimed to select tomato genotypes resistant to Tuta absoluta (Meyrick) (Lepidoptera: Gelechiidae) due to nonpreference for oviposition and feeding, in choice and no-choice tests. The species used were Solanum lycopersicum L. (cv. Santa Clara, hybrids: Saladete Italian Ty Tyna, Santa Cruz Débora Ty, Salad Lumi, Saledete Italian Andrea Victory and Santa Cruz Ty Carina Ty), S. habrochaites S. Knapp \& D.M Spooner (lines PI 134417 and PI 134418) and S. pimpinellifolium L. (lines NAV 1062 and PI 126931). In tests of nonpreference for oviposition the number of eggs per plant was counted at 24, 48 and 72 hours after the release of adults. For the tests of nonpreference for feeding the attractiveness of the larva to the genotypes in each replicate was assessed at 1,3 , $5,10,30,60,120,360 ; 720$ and 1440 minutes after the release of larvae and mass consumed by the larva. It was found that the tomato genotypes evaluated did not present nonpreference resistance for oviposition. However, the genotype PI 134417 presented nonpreference resistance for feeding.

KEY WORDS: Host plant resistance, types of resistance, allelochemical.

\section{INTRODUÇÃO}

A praga mais importante do tomateiro (Solanum lycopersicum L.) é a traça-do-tomateiro, Tuta absoluta (Meyrick) (Lepidoptera: Gelechiidae) (GonçALVES Neto et al., 2010), que se estabeleceu no Peru, Chile, Argentina, Uruguai, Paraguai, Bolívia, Colômbia e Venezuela no final da década de sessenta (VARGAS, 1970). No Brasil, a primeira ocorrência de T. absoluta deu-se em meados de 1979 (MuszinsKi et al., 1982) e, na Europa, a introdução da praga ocorreu em 2007 em Valência, Espanha, o que criou graves problemas aos produtores de tomate (VIEIRA, 2008).

Esta praga pode ocasionar perdas de produção em níveis preocupantes, tanto pelos prejuízos causados, como também pela dificuldade de seu controle (IMENES et al., 1990; MALuf et al., 1997).

No Brasil, esta praga tem sido controlada normalmente através de aplicações múltiplas de inseticidas, o que é indesejável tanto por motivos econômicos quanto ambientais, já que as aplicações sucessivas afetam os inimigos naturais e aumentam a possibi- 
lidade de desenvolvimento de populações da praga resistentes aos inseticidas (THOMAZINI et al., 2001).

Assim, a resistência de plantas a insetos é uma alternativa no controle desta praga e pode ser utilizada com outras táticas de controle, diminuindo sua população e minimizando os efeitos adversos de produtos químicos no meio ambiente (LARA, 1991).

Para se defender dos ataques, as plantas podem desencadear mecanismos que influenciam o comportamento dos insetos, sintetizando produtos químicos naturais ou aleloquímicos, que lhes conferem proteção contra uma grande variedade de herbívoros (WINK, 1988). Estes aleloquímicos podem desencadear um efeito metabólico tóxico (antibiose) ou deterrente (não preferência) sobre os insetos herbívoros (RosentHAL; BERENBAUM, 1992). Uma planta apresenta resistência do tipo não preferência quando é menos preferida pelo inseto para alimentar-se, ovipositar ou abrigar-se, do que outra em igualdade de condições, e apresenta antibiose quando contém substância(s) prejudicial(is) ao desenvolvimento do inseto (PANDA; KHUSH, 1995).

Várias espécies do gênero Solanum possuem os tipos de resistência antibiose e não preferência, estando relacionadas essencialmente com a ação de substâncias químicas presentes nos tricomas foliares das plantas (GIANFAGna et al., 1992; Ecole et al., 1999). Híbridos de tomateiro com teores intermediários de acilaçúcares e com potencial comercial já foram obtidos a partir do cruzamento interespecífico entre LA 716 Solanum pennelli vs Solanum lycopersicum L (MAciel et al., 2010; MACIEL et al., 2011) Além disso, características físicas (espessura da camada cuticular) e químicas dos frutos e o hábito de crescimento também podem estar envolvidos (LeITE et al., 2003).

As espécies S. lycopersicum, S. habrochaites S. Knapp \& D.MSpooner e S. pimpinellifolium L podem ser exploradas como fontes de resistência a T. absoluta (LourenÇÃo et al., 1984; Eigenbrode; TRUMBLE, 1993; GiUstolin; VendRAMIM, 1994; Leite et al., 1995; PicANÇO et al., 1995). Essas espécies silvestres conservam os genes envolvidos na biossíntese de potentes defesas químicas que conferem resistência a uma grande variedade de insetos (Gray et al., 1999).

Solanum lycopersicum, apesar de apresentar menor resistência comparada às outras espécies, possui grande vantagem de ser utilizada no melhoramento, devido às características agronômicas desejáveis, o que não ocorre nas espécies selvagens (LEITE, 2004). Como exemplo disso, algumas variedades de S. lycopersicum, como Gigante Orita e Príncipe Gigante, apresentam resistência a algumas pragas, entre as quais Helicoverpa zea (Boddie), Macrosiphum euphorbiae (Thomas), Spodoptera exigua (Hübner), Tetranychus urticae (Koch) e T. absoluta (ForNASIER et al., 1986; EIgENBROdE; TRUMBLE, 1993, 1994).
MACiEL et al. (2011), avaliando híbridos de tomateiro, verificaram que quatro deles, TEX-298, TEX-310, TEX-315 e TEX-316, mostraram-se mais resistentes a T. absoluta em comparação às testemunhas comerciais, Débora Max, Bravo, Bônus, Kombat, Atyna e Santa Clara.

Deste modo, o objetivo deste trabalho foi avaliar a resistência dos tipos não preferência para oviposição e alimentação em genótipos de Solanum spp. a T. absoluta, em testes com e sem chance de escolha.

\section{MATERIAL E MÉTODOS}

Os experimentos foram conduzidos em laboratório, à temperatura de $25 \pm 1^{\circ} \mathrm{C}$, UR de $70 \pm 10 \%$ e fotofase de 12h. Foram utilizadas as espécies de tomateiro S. lycopersicum (cv. Santa Clara suscetível e cinco híbridos: Saladete Italiano Ty Tyna, Santa Cruz Débora Ty, Salada Lumi, Saladete Italiano Andrea Victory e Santa Cruz Ty Carina Ty), S. habrochaites (linhagens PI134418 e PI134417) e S. pimpinellifolium (linhagens NAV 1062 e PI 126931), cultivadas em vasos $(40 \times 20 \mathrm{~cm})$ em casa de vegetação. As plantas foram utilizadas quando se apresentavam com 60 dias após a emergência.

T. absoluta foi criada em gaiolas de vidro retangulares $(0,4 \mathrm{~m} \times 0,4 \mathrm{~m}$ de base e $0,5 \mathrm{~m}$ de altura) com uma abertura lateral revestida com tecido voile. Folíolos de tomateiro foram retirados das plantas cultivadas em casa de vegetação, e suas hastes mergulhadas em potes de vidro, de $10 \mathrm{~cm}$ de altura e $4 \mathrm{~cm}$ de diâmetro, contendo água e fechados com algodão hidrófobo. Estes foram colocados no interior dessas gaiolas, onde os adultos foram liberados, obtendo-se os ovos. As plantas ovipositadas foram transportadas para outra gaiola de mesmas dimensões, para a eclosão das larvas. Ao atingir a fase de pupa, estas foram deixadas no interior dessas gaiolas com as plantas secas, até a emergência dos adultos, os quais novamente foram liberados nas gaiolas de oviposição (MirANDA et al., 1998). Os adultos foram alimentados com solução de mel a $10 \%$, e as larvas com folhas do cultivar Santa Cruz Kada Paulista.

Testes de não preferência para oviposição de $T$. $a b s o l u t a$, com e sem chance de escolha. Os ensaios foram realizados utilizando-se dez tratamentos, correspondentes aos genótipos, e cinco repetições.

O teste de não preferência para oviposição com chance de escolha foi conduzido em gaiolas de vidro retangulares $(0,4 \mathrm{~m} \times 0,4 \mathrm{~m}$ de base e $0,5 \mathrm{~m}$ de altura) com uma abertura lateral revestida com tecido voile. Em cada repetição, as plantas de tomateiro foram dispostas de forma circular, eliberados dois casais de adultos por genótipo de T. absoluta recém-emergidos no centro da gaiola. 
O ensaio, sem chance de escolha, foi conduzido em gaiolas cilíndricas de plástico, tendo as dimensões de $15 \mathrm{~cm}$ de diâmetro e $20 \mathrm{~cm}$ de altura. Foi acondicionada uma planta do genótipo por gaiola e liberados dois casais de adultos de T. absoluta recém-emergidos. Os adultos foram alimentados com solução de mel a 10\%.

Em ambos os ensaios, foram contados o número de ovos por planta com auxílio de um estereoscópico às 24,48 e 72 horas após a liberação dos adultos.

Testes de não preferência para alimentação de $T$. absoluta, com e sem chance de escolha. Os ensaios de não preferência para alimentação foram realizados com larvas de 12 dias de idade, utilizando-se dez tratamentos, correspondentes aos genótipos, e dez repetições.

O teste com chance de escolha foi conduzido em bandeja de alumínio de $30 \mathrm{~cm}$ de diâmetro e $5 \mathrm{~cm}$ de altura, forrando o fundo com papel filtro umedecido. Os folíolos de cada genótipo foram dispostas circularmente nas arenas (bandejas). No centro, foram liberadas duas larvas por genótipo, vedando-se em seguida a arena com papel filme.

O teste sem chance de escolha foi conduzido em placa de Petri de $6 \mathrm{~cm}$ de diâmetro, forrando o fundo com papel filtro umedecido, e uma folha do genótipo correspondente colocada no centro de cada placa de Petri, onde foram liberadas duas larvas.

Para a obtenção da massa consumida, desenharam-se os folíolos de cada genótipo em papel sulfite, e depois foram fornecidas as larvas. Ao término do teste, o que sobrou dos folíolos, após o consumo das larvas, foi novamente desenhado sobre o desenho dos folíolos inteiros. Posteriormente, recortou-se a parte consumida em papel sulfite, pesando-a em balança analítica.
Emambos os testes, foram avaliados a atratividade das larvas nos tratamentos, em cada repetição, após 1, 3, 5, 10, 30, 60, 120, 360, 720 e 1440 minutos, após a liberação. Quando cerca de $70 \%$ da área foliar foram consumidas em qualquer um dos tratamentos, o experimento foi encerrado.

Em todos os testes, os dados foram submetidos à análise de variância, pelo teste $\mathrm{F}$ e, quando significativo, as médias foram comparadas pelo teste de Tukey, ao nível de 5\% de probabilidade. Os dados de número de ovos e número de insetos atraídos de T. absoluta foram transformados em $(x+0,5)^{1 / 2}$ sendo tabelados os dados originais.

\section{RESULTADOS E DISCUSSÃO}

Testes de não preferência para oviposição de $T$. absoluta, com e sem chance de escolha. No teste com chance de escolha (Tabela 1), houve diferenças significativas somente na avaliação de ovos 48 horas após a liberação dos adultos, onde Lumi apresentou-se com a média maior de ovos (26,2 ovos), diferenciando-se de Tyna ( 5,6 ovos). Nas avaliações com 24 e 72 horas, Tyna também apresentou tendências de valores mais baixos de número de ovos, sendo, respectivamente, de 6,6 e 11,4 ovos.

No teste sem chance de escolha para oviposição (Tabela 2), não houve diferenças significativas entre os genótipos, mostrando serem eles igualmente ovipositados. Estes resultados são diferentes daqueles encontrados por THOMAZINI et al. (2001) que, em teste com o cultivar Santa Clara suscetível e linhagem PI 134417, encontraram diferenças significativas entre estas, tanto no teste com chance de escolha como no teste sem chance, destacando-se o último como menos ovipositado.

Tabela 1 - Número médio ( \pm EP) de ovos de T. absoluta às 24, 48 e 72 horas após a liberação dos adultos em diferentes genótipos de tomateiro, em teste com chance de escolha. Temp.: $25 \pm 1^{\circ} \mathrm{C}$, UR: $70 \%$ e fotofase: $12 \mathrm{~h}$.

\begin{tabular}{lccc}
\hline Genótipo & $\mathrm{N}^{\circ}$ ovos após 24 horas $^{1}$ & $\mathrm{~N}^{\circ}$ ovos após 48 horas $^{1}$ & $\mathrm{~N}^{\circ}$ ovos após 72 horas $^{1}$ \\
\hline NAV 1062 & $20,8 \pm 5,57 \mathrm{a}$ & $25,6 \pm 10,80 \mathrm{ab}$ & $42,0 \pm 10,17 \mathrm{a}$ \\
PI 134418 & $10,4 \pm 2,82 \mathrm{a}$ & $23,6 \pm 3,72 \mathrm{ab}$ & $29,2 \pm 7,66 \mathrm{a}$ \\
PI 126931 & $14,0 \pm 2,70 \mathrm{a}$ & $16,0 \pm 4,96 \mathrm{ab}$ & $14,8 \pm 11,17 \mathrm{a}$ \\
PI 134417 & $7,0 \pm 3,80 \mathrm{a}$ & $8,6 \pm 2,46 \mathrm{ab}$ & $16,6 \pm 4,00 \mathrm{a}$ \\
Tyna & $6,6 \pm 3,23 \mathrm{a}$ & $5,6 \pm 1,93 \mathrm{~b}$ & $11,4 \pm 4,77 \mathrm{a}$ \\
Débora & $7,4 \pm 3,04 \mathrm{a}$ & $16,8 \pm 3,26 \mathrm{ab}$ & $14,6 \pm 4,25 \mathrm{a}$ \\
Carina & $10,6 \pm 2,92 \mathrm{a}$ & $21,4 \pm 6,41 \mathrm{ab}$ & $34,2 \pm 13,63 \mathrm{a}$ \\
Lumi & $10,4 \pm 5,34 \mathrm{a}$ & $6,2 \pm 5,08 \mathrm{a}$ & $26,8 \pm 8,09 \mathrm{a}$ \\
Andrea Victory & $13,0 \pm 5,77 \mathrm{a}$ & $22,4 \pm 2,63 \mathrm{ab}$ & $24,2 \pm 4,62 \mathrm{a}$ \\
Santa Clara & $11,0 \pm 4,21 \mathrm{a}$ & $23,2 \pm 3,05 \mathrm{ab}$ & $25,2 \pm 9,00 \mathrm{a}$ \\
\hline F & $1,01^{\mathrm{ns}}$ & $2,86^{*}$ & $1,84^{\mathrm{ns}}$ \\
\hline C.V. (\%) & 46,26 & 28,52 & 34,49 \\
\hline
\end{tabular}

Médias seguidas da mesma letra não diferem entre si pelo teste de Tukey a $5 \%$ de probabilidade.

${ }^{1}$ Dados originais. Para análise os dados foram transformados em $(x+0,50)^{1 / 2}$ 
Tabela 2 - Número médio ( \pm EP) de ovos de T. absoluta às 24, 48 e 72 horas após a liberação dos adultos em diferentes genótipos de tomateiro, em teste sem chance de escolha. Temp.: $25 \pm 1^{\circ} \mathrm{C}$, UR: $70 \%$ e fotofase: $12 \mathrm{~h}$.

\begin{tabular}{|c|c|c|c|}
\hline Genótipo & $\mathrm{N}^{\circ}$ ovos após 24 horas $^{1}$ & $\mathrm{~N}^{\circ}$ ovos após 48 horas $^{1}$ & $\mathrm{~N}^{\circ}$ ovos após 72 horas $^{1}$ \\
\hline NAV 1062 & $11,4 \pm 3,6 \mathrm{a}$ & $12,0 \pm 3,11 \mathrm{a}$ & $35,2 \pm 7,47 \mathrm{a}$ \\
\hline PI 134418 & $7,0 \pm 3,89$ a & $20,4 \pm 3,35 \mathrm{a}$ & $21,2 \pm 2,72 \mathrm{a}$ \\
\hline PI 126931 & $1,4 \pm 0,77 \mathrm{a}$ & $22,0 \pm 6,65 \mathrm{a}$ & $22,4 \pm 3,41 \mathrm{a}$ \\
\hline PI 134417 & $0,0 \pm 0,00 \mathrm{a}$ & $22,4 \pm 6,40 \mathrm{a}$ & $13,6 \pm 1,43 a$ \\
\hline Tyna & $7,0 \pm 4,89 a$ & $26,0 \pm 10,3 \mathrm{a}$ & $25,6 \pm 8,36 a$ \\
\hline Débora & $7,0 \pm 4,89 a$ & $19,2 \pm 8,34 \mathrm{a}$ & $22,6 \pm 6,17 \mathrm{a}$ \\
\hline Carina & $1,4 \pm 6,04 a$ & $22,0 \pm 6,79 a$ & $15,6 \pm 9,02 \mathrm{a}$ \\
\hline Lumi & $6,8 \pm 0,75 a$ & $20,2 \pm 7,01 \mathrm{a}$ & $20,8 \pm 3,78 a$ \\
\hline Andrea Victory & $3,0 \pm 3,97 \mathrm{a}$ & $18,2 \pm 5,26 \mathrm{a}$ & $21,8 \pm 4,46 \mathrm{a}$ \\
\hline Santa Clara & $1,0 \pm 1,48 \mathrm{a}$ & $9,20 \pm 5,95 \mathrm{a}$ & $36,8 \pm 6,57 \mathrm{a}$ \\
\hline $\mathrm{F}$ & $1,38^{\text {ns }}$ & $0,73^{\text {ns }}$ & $1,61^{\mathrm{ns}}$ \\
\hline C.V. $(\%)$ & 78,30 & 43,21 & 29,59 \\
\hline
\end{tabular}

Médias seguidas da mesma letra não diferem entre si pelo teste de Tukey a $5 \%$ de probabilidade.

${ }^{1}$ Dados originais. Para análise os dados foram transformados em $(x+0,50)^{1 / 2}$

Gilardón et al. (2001), avaliando a espécie de tomate cultivado $S$. lycopersicum cultivar Uco Plata, suscetível à traça-do-tomateiro, e S. habrochaites PI134417, resistente, com tricomas removidos e com presença de tricomas, não encontraram diferenças significativas de oviposição. Desta forma, segundo os mesmos autores, a presença de tricomas glandulares e de seus exsudatos não induziu efeito inibidor de oviposição.

Esses resultados contrariam os obtidos por MALUF et al. (1997), que obtiveram menor número de ovos em plantas de Solanum com maiores concentrações de 2-tridecanona, do que aquelas com baixas concentrações. Oliveira et al. (2012) relataram que uma estirpe rica em 2-tridecanona, zingibereno e acilaçúcares (aleloquímicos) poderá ser um genótipo de tomate com resistência à mariposa.

TosCANo et al. (2002) estudaram a resistência de diferentes espécies de Solanum em relação à atratividade eà oviposição de B. tabaci biótipo $\mathrm{B}$, constatando que os genótipos altamente resistentes, pertencentes a S. pennellii (Corr.) (LA 716) e S. habrochaites (PI 134417), foram os menos preferidos para oviposição. FANCELLI et al. (2003) também constataram, em estudo de preferência de oviposição de B. tabaci, que S. pennellii e $S$. habrochaites possuem resistência do tipo não preferência para oviposição.

MACIEL et al. (2011) verificaram que a oviposição da traça-do-tomateiro foi, em geral, menor nos híbridos experimentais e na linhagem TOM-687 do que nas linhagens com baixo teor de acilaçúcar (TOM-650, TOM-694, TOM-699 e TOM-700) ou nas testemunhas comerciais (Bravo, Bônus e Santa Clara).

Testes de não preferência para alimentação de T. absoluta, com e sem chance de escolha. A não preferência para alimentação em teste com chance de escolha (Tabela 3), no que se refere à atratividade, apresentou diferenças significativas em todas as ava- liações, com exceção da realizada após 720 minutos da liberação das larvas.

Andrea Victory foi o genótipo que se apresentou como o mais preferido para alimentação, com número de larvas atraídas variando de 4,4 a 4,8 , diferenciando-se de NAV1062, Tyna, Lumi, Débora, Carina e PI 126931, e dentre estes, o último obteve menor quantidade de larvas atraídas, variando de 0,7 a 1,0 .

Com relação à massa foliar consumida pelas larvas, não houve diferença significativa no teste com chance de escolha, mostrando ser igualmente consumida (Tabela 3).

A não preferência para alimentação sem chance de escolha (Tabela 4), no que se refere à atratividade, apresentou diferenças significativas somente nos tempos de 15 e 30 minutos, após a liberação das larvas. Em ambos os tempos, o genótipo Carina foi o menos atrativo (1,5 larva), diferenciando-se de PI 126931, Débora e NAV 1062 (2,0 larvas).

A massa foliar consumida pelas larvas apresentou diferenças significativas no teste sem chance de escolha (Tabela 4). O genótipo PI 134417 (1,1 g) destacou-secom o menor consumo, diferenciando-se da testemunha Santa Clara (2,7 g) e dos genótipos NAV 1062, PI 134418, PI 126931, Tyna, Débora, Carina e Andrea Victory. O genótipo Lumi também se destacou com baixo consumo de massa foliar pelas larvas (1,3 g), de modo semelhante ao PI 134417, diferenciando-se da testemunha e dos demais genótipos (Tabela 4).

Não foi observada movimentação de larvas nos primeiros minutos de avaliação do teste com chance de escolha, e sim um estabelecimento delas nos genótipos desde o instante em que foram liberadas. Esse fato mostra que os voláteis emitidos pelas folhas não afetaram o comportamento das larvas, uma vez que, segundo LARA (1991), é a primeira fase da seleção 


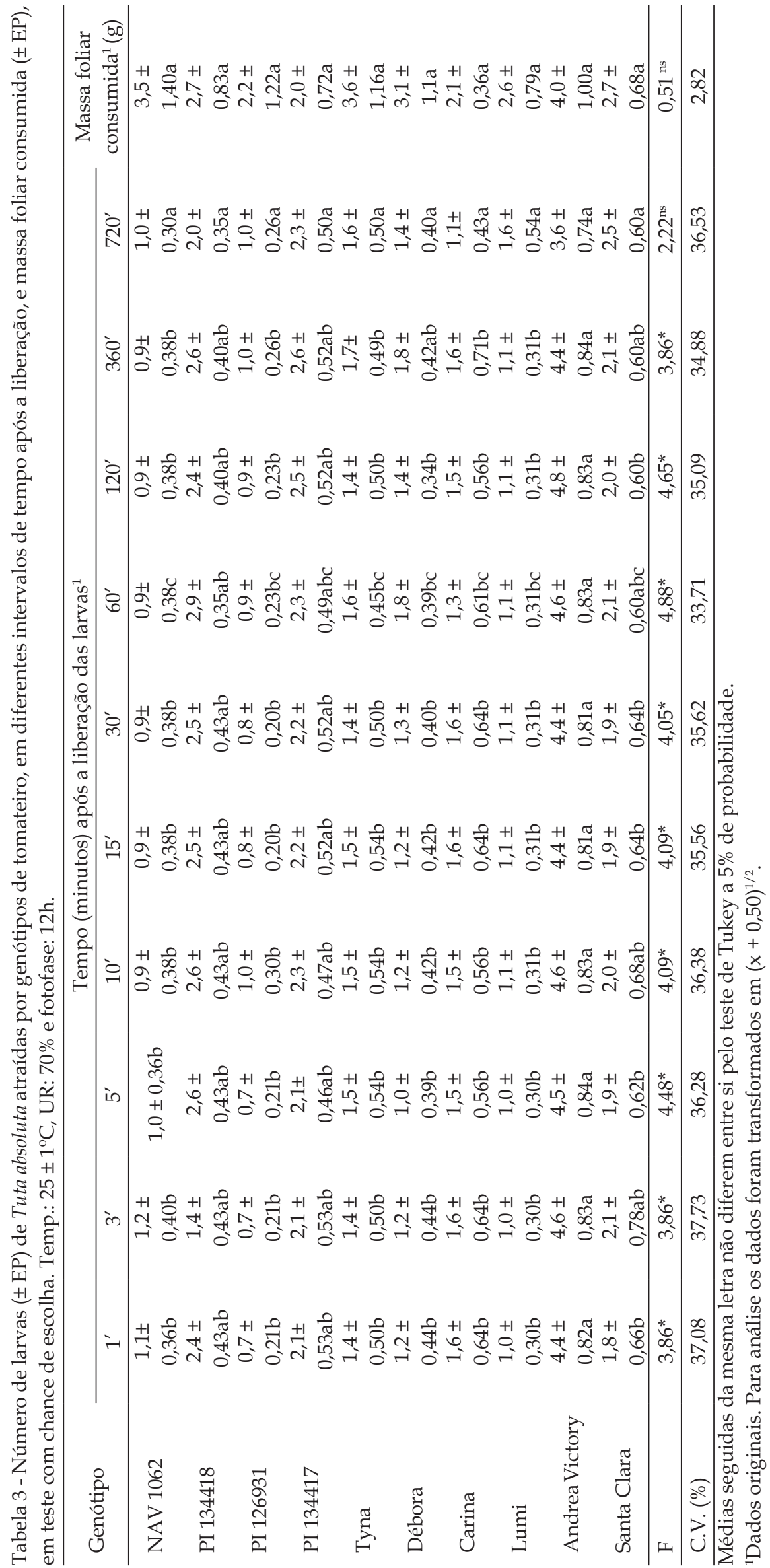




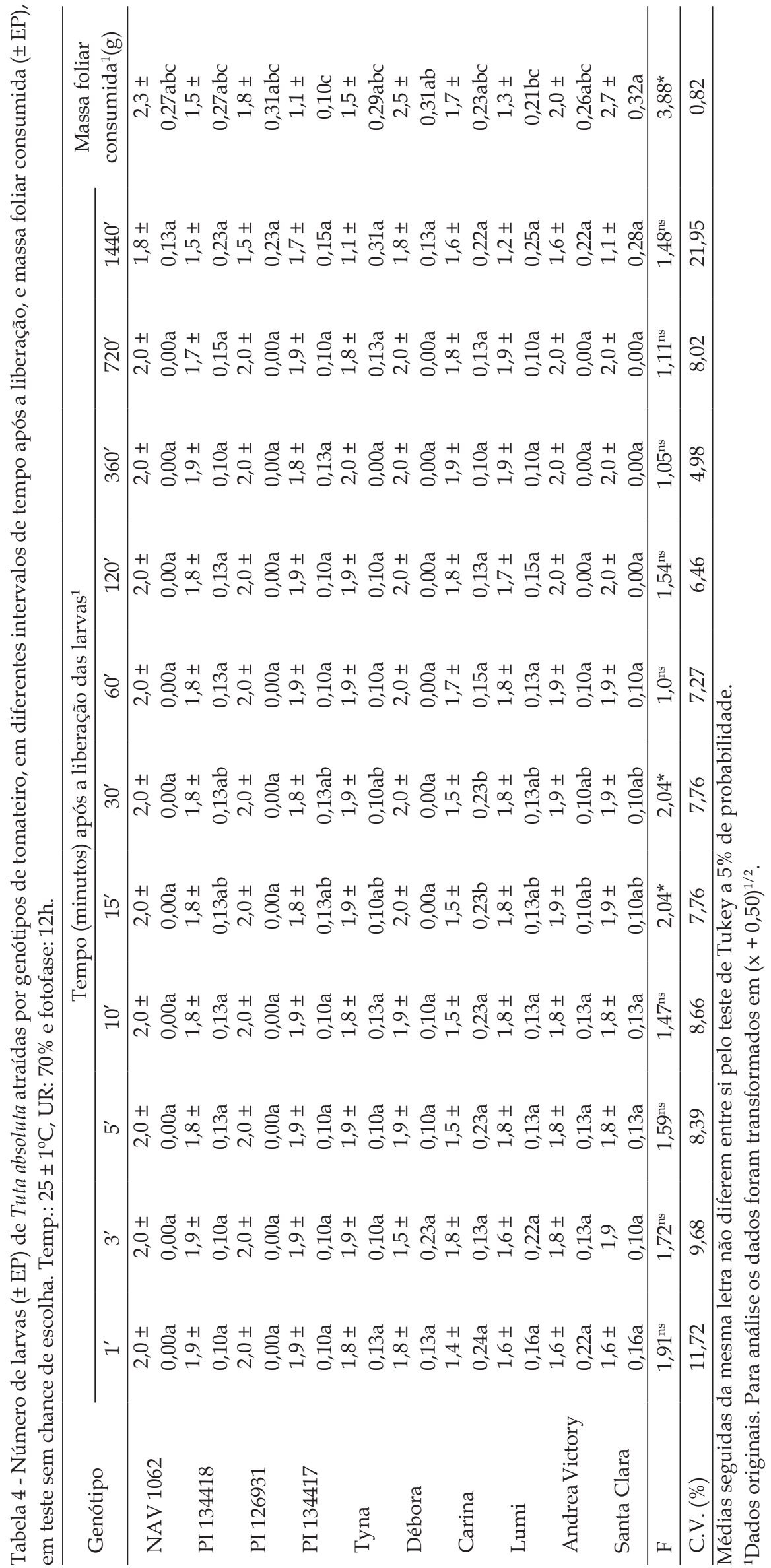


hospedeira para alimentação e/ ou oviposição de um inseto fitófago. Estefato também ocorreu no teste sem chance de escolha, aonde as larvas, em sua maioria, locomoveram-se para o alimento ali existente e permaneceram alimentando-se, demonstrando que os genótipos não tiveram influência na atratividade das larvas de T. absoluta.

OLIVEIRA et al. (2009) constataram que os acessos de tomateiro BGH-55; 83; 225; 227; 320; 406; 603; 674; 1282; 1497; 1499; 1708; 1532; 1989; 1990; 7235 e 7238 possuem resistência a T. absoluta, pois observaram, nestes acessos, menor porcentagem de folhas minadas que nas variedades TOM 601 e Moneymaker, consideradas resistentes. Todos esses acessos, exceto BGH-1499, foram também agrupados entre os resistentes para número de minas grandes por folha, sugerindo que estes acessos podem apresentar resistência do tipo não preferência para alimentação a T. absoluta. Segundo Leite et al. (1995), alto número de minas pequenas pode ser indicativo de não adequação alimentar do inseto à planta.

ECOLE et al. (1999) verificaram que o acesso LA 1777 de S. habrochaites possui alto número de minas pequenas e baixo número de minas grandes em comparação com os cultivares Santa Clara e IPA-5, indicando que as causas dessa resistência podem estar relacionadas à presença de compostos com ação inibidora (deterrente) da alimentação dos insetos. GonçALVES Neto et al. (2010) constataram que plantas de tomateiro com alto teor de acilaçúcares demonstraram níveis mais altos de resistência, apresentando menores lesões nos folíolos, porcentagem de folíolos atacados.

\section{CONCLUSÕES}

Pelos resultados obtidos e nas condições em que o experimento foi conduzido, pode-se concluir que: -os genótipos de tomateiro testados não apresentam resistência do tipo não preferência para oviposição; -o genótipo PI 134417 apresenta resistência do tipo não preferência para alimentação.

\section{AGRADECIMENTOS}

Ao Conselho Nacional de Desenvolvimento Cientifico e Tecnológico (CNPq), pela concessão da bolsa de mestrado à segunda autora e de produtividade em pesquisa ao primeiro e terceiro autores.

\section{REFERÊNCIAS}

ECOLE, C.C.; PICANÇO, M.; JHAM, G.N.; GUEDES, R.N.C. Variability of Lycopersicon hirsutum f. typicum and possible compounds involved in its resistance to Tuta absoluta. Agricultural and Forest Entomology, v.1, n.4 p.249-254, 1999.

EIGENBRODE, S.D.; TRUMBLE, J.T. Antibiose to beet armyworm (Spodoptera exigua) in Lycopersicon acessions. Horticultural Science, v.28, n.5, p.932-934, 1993.

EIGENBRODE, S.D.; TRUMBLE, J.T. Fruit-based tolerance to damage by beet armyworm (Lepidoptera: Noctuidae) in tomato. Environmental Entomology, v.23, n.4, p.937-942, 1994.

FANCELLI, M.; VENDRAMIM, J.D.; LOURENÇÃO, A.L.; DIAS, C.T.S. Atratividade e preferência para oviposição de Bemisia tabaci (Gennadius) (Hemiptera: Aleyrodidae) biótipo B em genótipos de tomateiro. Neotropical Entomology, v.32, n.2, p.319-328, 2003.

FORNAZIER, M.J.; DESSAUNE FILHO, N.; PEREIRA, E.B. Perdas ocasionadas pela traça-do-tomateiro Scrobipalpula absoluta em diversas variedades de tomate. Cariacica: EMCAPA, 1986. 46p. (Comunicado Técnico).

GIANFAGNA, T.J.; CARTER, C.D.; SACALIS, J.N. Temperature and photoperiod influence on trichome density and sesquiterpene content of Lycopersicon hirsutum f. hirsutum. Plant Physiology, v.100, n.4, p.1403-1405, 1992.

GILARDÓN, E.; POCOVI, M.; HERNÁNDEZ, C.; OLSEN, A. Papel dos tricomas glandulares da folha do tomateiro na oviposição de Tuta absoluta. Pesquisa Agropecuária Brasileira, v.36, n.3, p.585-588, 2001.

GIUSTOLIN, T.A.; VENDRAMIM, J.D. Efeito de duas espécies de tomateiro na biologia de Scrobipalpuloides absoluta (Meyrick). Anais Sociedade Entomológica do Brasil, v.23, n.3, p.511-517, 1994.

GONÇALVES NETO, A.C.; SILVA, V.F.; MALUF, W.R.; MACIEL, G.M.; NIZIO, D.A.C.; GOMES, L.A.A.; AZEVEDO, S.M. Resistência à traça-do-tomateiro em plantas com altos teores de acilaçúcares nas folhas. Horticultura Brasileira, v.28, n.2, p.203-208, 2010.

GRAY, L.; COLLAVINO, G.; GILARDON, E.; HERNANDEZ, C.; OLSEN, A.; SIMÓN, G. Heredabilidad de la resistencia a la polilla del tomate (Tuta absoluta Meyrick) y su correlación genética con caracteres de calidad, en descendencias de cruzas interespecíficas del género Lycopersicon. I nvestigación Agraria. Producción y Protección Vegetales, v.14, n.3, p.445-451, 1999.

IMENES, S.D.L.; UCHOA-FERNANDES, M.A.; CAMPOS, T.B.; TAKEMATSU, A.P. Aspectos biológicos e comportamentais da traça-do-tomateiro Scrobipalpula absoluta (Meyrick, 1917), (Lepidoptera-Gelechiidae). Arquivos do Instituto Biológico, São Paulo, v.57, n.1/2, p.63-68, 1990. 
LARA, F.M. Princípios de resistência de plantas a insetos. 2. ed. São Paulo: Ícone, 1991. 336p.

LEITE, G.L.D. Resistência de tomates a pragas. Unimontes Científica, v.6, n.2, p.129-140, 2004.

LEITE, G.L.D.; PICANÇO, M.; SILVA, D.J.H.; MATA, A.C; JHAM, G.N. Distribuição de oviposição de Scrobipalpuloides absoluta no dossel de Lycopersicon esculentum, L. hirsutum e L. peruvianum. Horticultura Brasileira, v.13, n.1, p.47-51, 1995.

LEITE, G.L.D.; COSTA, C.A.; ALMEIDA, C.I.M.; PICANÇO, M. Efeito da adubação sobre a incidência de traça-do-tomateiro e alternaria em plantas de tomate. Horticultura Brasileira, v.21, n.3, p.448-451, 2003.

LOURENÇÃO, A.L.; NAGAI, H.; ZULO, M.A.T. Fontes de resistência a Scrobipalpula absoluta (Meyrick, 1917) em tomateiro. Bragantia, v.43, n.2, p.569-577, 1984.

MACIEL, G.M.; MALUF, W.R.; SILVA, V.F.; GONÇALVES NETO, Á.C.; NOGUEIRA, D.W.; GOMES, L.A.A.. Heterose e capacidade combinatória de linhagens de tomateiro ricas em acilaçúcares. Ciência e Agrotecnologia, v.34, n.5, p.1161-1167, 2010.

MACIEL, G.M.; MALUF, W.R.; SILVA, V.F.; GONÇALVES, A.C.; GOMES, L.A.A. Híbridos pré-comerciais resistentes à traça obtidos de linhagem de tomateiro rica em acilaçúcares. Horticultura Brasileira, v.29, n.2, p.333-339, 2011.

MALUF, W.R.; BARBOSA, L.V.; SANTA-CECÍLIA L.V.C. 2-Tridecanona-mediated mechanism of resistance to the South American tomato pinworm Srobipalpuloides absoluta (Meyrick, 1917) (LepidopteraGelechiidae) in Lycopersicon spp. Euphytica, v.93, n.2, p.189-194, 1997.

MIRANDA, M.M.M.; PICANÇO, M.C.; ZANUNCIO, J.C.; GUEDES, R.N.C. Ecological life table of Tuta absoluta (Meyrick) (Lepidoptera: Gelechiidae). Biocontrol Science and Technology, v.8, n.3, p.597-606, 1998.

MUSZINSKI, T.; LAVENDOWSKI, I.M.; MASCHIO, L.M.A. Constatação de Scrobipalpula absoluta (Meyrick, 1917) (Gnorimoschema absoluta) (Lepidoptera: Gelechiidae), como praga do tomateiro (Lycopersicon esculentum Mill.), no litoral do Paraná. Anais da Sociedade Entomológica do Brasil, v.11, n.2, p.291-292, 1982.
OLIVEIRA, F.A. de; SILVA, D.J.H.; PICANÇO, M.C.; JHAM, G.N. Resistência tipo antixenose em acessos de tomateiro à Tuta absoluta. Magistra, v.21, n.1, p.8-17, 2009.

OLIVEIRA. C.M.; ANDRADE JÚNIOR, V.C.; MALUF, W.R.; NEIVA, I.P.; MACIEL, G.M. Resistance of tomato strains to the moth Tuta absoluta imparted by allelochemicals and trichome density. Ciência e Agrotecnologia, v.36, n.1, p.45-52, 2012.

PANDA, N.; KHUSH, G.S. Host plant resistance to insects. Oxford: Oxford University Press, 1995. 448p.

PICANÇO, M.C.; SILVA, D.J.H.; LEITE, G.L.D.; MATA, A.C.; JHAM, G.N. Intensidade de ataque de Scrobipalpula absoluta (Meyrick, 1917) ao dossel de três espécies de Tomateiro. Pesquisa Agropecuária Brasileira, v.30, n.2, p.429-433, 1995.

ROSENTHAL, G.A.; BERENBAUM, M. Herbivores: their interactions with secondary plant metabolites. San Diego: Academic, 1992. v.2, 477p.

THOMAZINI, A.P.B.W.; VENDRAMIM, J.D.; BRUNHEROTTO, R.; LOPES, M.T.R. Efeito de genótipos de tomateiro sobre a biologia e oviposição de Tuta absoluta (Meyrick) (Lep.: Gelechiidae). Neotropical Entomology, v.30, n.2, p.283-288, 2001.

TOSCANO, L.C.; BOIÇA JUNIOR, A.L.; MARUYAMA, W.I. Nonpreference of whitefly for oviposition in tomato genotypes. Scientia Agrícola, v.59, n.4, p.677-681, 2002.

VARGAS, H.C. Observaciones sobre la biologia y enemigos naturales de la polilla del tomate, Gnorimoschema absoluta (Meyrick) (Lepidoptera: Gelechiidae). Idesia, v.1, n.1, p.75-110, 1970.

VIEIRA, M.M. Mineira do tomateiro (Tuta absoluta) uma nova ameaça à produção de tomate. In.: SEMINÁRIO INTERNACIONAL DO TOMATE DE INDUSTRIA, 5., 2008, Mora. Anais. Mora: 2008. p.1-5.

WINK, M. Plant breeding importance of plant secondary metabolites for protection against pathogens and herbivores. Theoretical Applied Genetics, v.75, n.2, p.225-233, 1988.

Recebido em 8/8/11

Aceito em 29/10/12 